\title{
Fat accumulation in Caenorhabditis elegans is mediated by SREBP homolog SBP-1
}

\author{
Toshihisa Nomura $\cdot$ Makoto Horikawa $\cdot$ \\ Satoru Shimamura · Teppei Hashimoto • \\ Kazuichi Sakamoto
}

Received: 27 July 2009/Accepted: 22 October 2009/Published online: 20 November 2009

(C) Springer-Verlag 2009

\begin{abstract}
Research into the metabolism of fats may reveal potential targets for developing pharmaceutical approaches to obesity and related disorders. Such research may be limited, however, by the cost and time involved in using mammalian subjects or developing suitable cell lines. To determine whether invertebrates could be used to carry out such research more efficiently, we investigated the ability of Caenorhabditis elegans (C. elegans) to accumulate body fat following the consumption of excess calories and the mechanisms it uses to metabolize fat. C. elegans worms were grown on media containing various sugars and monitored for changes in body fat and expression of $s b p-1$, a homolog of the mammalian transcription factor SREBP-1c, which facilitates fat storage in mammals. The fat content increased markedly in worms exposed to glucose. In situ analysis of gene expression in transgenic worms carrying the GFP-labeled promoter region of $s b p-1$ revealed that $s b p-1$ mRNA was strongly expressed in the intestine. An $s b p-1$ knockdown caused a reduction in body size, fat storage, and egg-laying activity. RT-PCR analysis revealed a considerable decrease in the expression of fatty acid synthetic genes (including elo-2, fat-2, and fat-5) and a considerable increase of starvation-inducible gene acs-2. Normal egg-laying activity and acs-2 expression were restored on exposure to a polyunsaturated fatty acid. These findings suggest that SBP-1 and SREBP regulate the amount and composition of fat and response to starvation in a similar manner. Thus, C. elegans may be an appropriate subject for studying the metabolism of fats.
\end{abstract}

T. Nomura - M. Horikawa - S. Shimamura - T. Hashimoto ·

K. Sakamoto $(\bowtie)$

Graduate School of Life and Environmental Sciences,

University of Tsukuba, Tsukuba, Ibaraki, Japan

e-mail: sakamoto@biol.tsukuba.ac.jp
Keywords Caenorhabditis elegans - SREBP-1c . SBP-1 - Obesity · Fat accumulation · Fatty acids

\section{Introduction}

The rapidly increasing prevalence of obesity in developed nations has been accompanied by an increased interest in the study of fat metabolism with the goal of identifying targets for the development of products that may prevent or cure obesity and conditions for which obesity is a risk factor (including type 2 diabetes mellitus and the dyslipidemias). Research activities may be limited, however, by the cost and the time involved in using mammalian subjects or developing suitable cell lines. The use of invertebrates may overcome both of these barriers to research. The nematode Caenorhabditis elegans, for example, may provide a more efficient means of screening research materials and medications and studying the metabolism of fat because of its short lifespan and the ease with which fat can be visualized in its body. The feasibility of using $C$. elegans in fat metabolism studies will depend, of course, on whether it accumulates fat when it consumes more energy than it needs and whether it uses metabolic pathways similar to those used in mammals to synthesize and store fat.

The process of converting excess energy into fat begins in mammals when insulin induces the translocation of the glucose transporter GLUT into the cell, thereby increasing intracellular glucose levels [1-5]. This is followed by an increase in sterol regulatory element-binding protein (SREBP)-1c basic helix-loop-helix-zipper (bHLH-zip) transcription factor [6-15]. SREBP-1c is transported to the nucleus, where it undergoes dimerization and then binds to the e-box and consensus sterol response element (SRE) $(15,16)$ regions of genes that contribute to fat synthesis 
including acyl-cocarboxylase (acc-1), fatty acid synthase (fas), several desaturases, long fatty acid elongase, and glycerol-3-phosphate-acyltransferase [16-23]. SREBP-1c also regulates the production of insulin receptor substrate (irs)-2 (a component of the insulin signal pathway) and, thus, promotes insulin resistance [24]. Because rat homolog of SREBP-1c is involved in adipocyte differentiation, it was called adipocyte determination and differentiation dependent (ADD1) [25]. These actions make SREBP-1c a potential target for the development of therapeutics for obesity and associated diseases.

SREBP-1c has been found in a variety of animals, including yeast, but it is not always involved with fat accumulation, functioning instead as a sensor of intracellular cholesterol and oxygen levels ( $[26,27,28])$. C. elegans has a homolog of SREBP: Y47D38.7/sbp-1/lpd-1. C. elegans nematodes lacking this gene demonstrate delayed growth, lower fat levels, and altered rates of expression of fat synthesis genes, specifically Acc-1, fas-1, fatty acid elongases (elo-5 and elo-6), and stearoyl-CoA desaturases (fat-6 and fat-7) [29-32]. Furthermore, it was recently reported that a co-activator, ARC105/MDT-15, is necessary for SREBP and SBP-1 activity in mammals and C. elegans, respectively [33]. These observations suggest that SBP-1 has the same function in C. elegans as SREBP-1c does in mammals.

Caenorhabditis elegans produces three $\Delta 9$ desaturases (fat-5, fat-6, and fat-7), as well as $\Delta 3, \Delta 5, \Delta 6$, and $\Delta 12$ desaturases; thus, it can produce multiple kinds of fatty acids [34-38]. By contrast, mammals lack $\Delta 3$ and $\Delta 12$ desaturases, which prevents them from producing polyunsaturated fatty acids (PUFAs) endogenously and makes it necessary for them to obtain PUFAs from food. These essential PUFAs include docosahexanoic acid (DHA), eicosapentanoic acid (EPA), linoleic acid, and $\alpha$-linolenic acid, all of which are necessary for normal nerve activity. Transcription of the genes that produce $\Delta 5, \Delta 6$, and $\Delta 9$ desaturases in mammals is controlled by SREBP-1c [18, 19]. This suggests that the expression of desaturases in C. elegans is regulated by SBP-1. The expression of fat- 6 and fat 7 is indeed regulated by SBP-1 [33]. However, the expression of these two genes (along with fat-5) is also controlled by two other transcription factors: nhr- 49 or nhr-80 [39-41]. sbp- 1 and $n h r-49$, in turn, are both regulated by the same co-activator (mdt-15) [33, 42].

The purpose of this study was to determine whether excess energy is stored as fat in C. elegans as it is in mammals and whether the expression of the srebp homolog $s b p-1$ also changes during the fat-accumulation process. We used RNA interference (RNAi) of $s b p-1$ to determine how SBP-1 affects relevant physiological phenomena and gene expression in C. elegans.

\section{Methods}

Worms and culture

Wild-type Caenorhabditis elegans Bristol N2 (Caenorhabditis Genetics Center, Minnesota, USA) were cultured at $20^{\circ} \mathrm{C}$ on NGM (Nematode Growth Medium) agar plated with $E$. coli OP50 as previously described [43]. Each worm was transferred on the new plate in each 7 days.

Synchronization of the growth stage

To synchronize the growth stage of nematode, adult worms were treated with $10 \% \mathrm{NaClO}$ solution [10 N NaOH/NaClO

Table 1 Primers for RT-PCR

\begin{tabular}{lll}
\hline Gene & Forward & Reverse \\
\hline$s b p-1$ & CATGAATTCATTCGAGGGAGACGTCCC & CATGAATTCCTGATGTGGAGTCATCGC \\
$f a t-1$ & CAGCTCGAGCACGGCTCCGGTCACCGG & CAGCTCGAGTGACTTTTCTGCCATGGG \\
$f a t-2$ & CAGCTCGAGCAATCCCTGAGCACTGC & CAGCTCGAGAGTCTTCCTCAGTAACCC \\
$f a t-3$ & CATGGATCCACAAGAATGCCTCCGGGC & CATGGATCCAATCCATCATCATGAAGC \\
$f a t-4$ & CAGCTCGAGAGAGCAAGAGCATGAGCC & CAGCTCGAGATCCATCCATAAGTCC \\
$f a t-5$ & CAGCTCGAGCGATTATATCTAAACAG & CAGCTCGAGCAGCATCAGTATCCGTCC \\
$f a t-6$ & CATGGATCCACGGCGGCCCAGAGACGC & CATGGATCCCAGTCCACTTGTGATGGC \\
$e l o-2$ & CATGGATCCCTCAATACCTGTTCATGG & CATGGATCCCAGCATCTGTATCAGTCC \\
$a c s-2$ & CATGGATCCCAAGTCCAGCAGCCACGC & CATGGATCCTCGACATCACAAAGGCCC \\
$g p d-1$ & AGTAAGCTTAATCCTCGTATCCCGCCG & AGTAAGCTTCCTGGCTGGCCACGTCGC \\
\hline
\end{tabular}

PCR was performed using the primers indicated as below under optimal amplification conditions $\left(95^{\circ} \mathrm{C}\right.$ for 5 min; $23-35$ cycles of $95^{\circ} \mathrm{C}$ for $1 \mathrm{~min}, 52^{\circ} \mathrm{C}$ for $30 \mathrm{~s}, 72^{\circ} \mathrm{C}$ for $1.5 \mathrm{~min} ; 72^{\circ} \mathrm{C}$ for $7 \mathrm{~min}$ ) for each gene. The PCR amplification of each cDNA was performed independently using three samples in triplicate 
$(10: 1)]$ at room temperature, until the skin of the individual of $80 \%$ was destroyed. The eggs were collected and cultured overnight in $\mathrm{S}$-basal $(0.1 \mathrm{~mol} / 1 \mathrm{NaCl}, 50 \mathrm{mmol} / 1$ potassium phosphate buffer) at $20^{\circ} \mathrm{C}$ until hatching.

Nile red assays

The synchronized L1 worms were cultured on media including 500-nM Nile red. Three or four days later, worms were collected, treated with $0.2 \%$ PFA solution, and observed under a fluorescence microscope (DMRXA, Leica) using N3 filter. Image analysis was performed using ImageJ, a public domain Java-based image-processing program inspired by NIH Image.

Effect of fatty acid

The sbp-1 RNAi worms were cultured on NGM plate containing $1 \mathrm{mM}$ fatty acid (stearic acid, oleic acid, or linoleic acid, WAKO) and $0.1 \%$ tergitol type NP-40 (SIGMA). After 3 or 4 days culture, the worms were subjected to Nile red analysis, the egg laying, RT-PCR, and GFP assays.

Construction of feeding RNAi plasmid

PCR was performed to amplify the $s b p-1$ cDNA regions using PCR-2720 (Applied Biosystems, Foster City, CA, USA). Primer was designed to have restriction site at $5^{\prime}$-end and to make PCR products with $\sim 500$ ntds in length. The amplified PCR products were digested by each restriction enzyme and subcloned into plasmid L4440 (provided from Fire laboratory) designed for feeding-RNAi (RNAi plasmid). The nucleotide sequences of plasmid DNA were analyzed by using Big Dye Terminator Cycle Sequencing Ready Reaction Kit (Applied Biosystems) and ABI PRISM 377 DNA Sequencer (Perkin Elmer Biosystems).
The primers were designed from DNA sequences according to the Wormbase database (http://www.wormbase.org). PCR $\left(95^{\circ} \mathrm{C}\right.$ for $5 \mathrm{~min} ; 25-30$ cycles of $95^{\circ} \mathrm{C}$ for $1 \mathrm{~min}, 52^{\circ} \mathrm{C}$ for $30 \mathrm{~s}, 72^{\circ} \mathrm{C}$ for $1.5 \mathrm{~min} ; 72^{\circ} \mathrm{C}$ for $7 \mathrm{~min}$ ) was performed using the following primers; sbp-1F, CATGAATTC ATTCGAGGGAGACGTCCC, sbp-1R, CATGAATTCCT GATGTGGAGTCATCG C.

\section{Bacteria-mediated RNAi}

Escherichia coli strain HT115 was transfected with RNAi plasmid and treated with $35 \mathrm{mM}$ IPTG (Isopropyl- $\beta$-Dthiogalactopyranoside, Wako, Chuo, Osaka, Japan) to induce the RNA expression. These transformants were plated on NGM agar containing $1 \mathrm{mM}$ IPTG and incubated at $37^{\circ} \mathrm{C}$ for $1 \mathrm{~h}$ (RNAi plate). L4440, an empty vector, was used as a negative control of RNAi. Because the $E$. coli HT115 transformant and the RNAi plate lose RNAi efficiency along with time, they were prepared newly in every experiment. After treatment of adult worms with $10 \%$ $\mathrm{NaClO}$ solution [10 N NaOH/NaClO (10:1)], eggs were collected and cultured overnight in S-basal $(0.1 \mathrm{~mol} / 1$ $\mathrm{NaCl}, 50 \mathrm{mmol} / \mathrm{l}$ potassium phosphate buffer) at $20^{\circ} \mathrm{C}$ until hatching. Hatched L1 larvae or adult worms were then cultured on NGM RNAi plates at $20^{\circ} \mathrm{C}$ to induce RNAi.

The movement analysis

The number of movements per 1 min of the pumping and the thrashing was counted under the microscope.

Egg-laying analysis: adult nematodes

L1 larva or adult nematode was cultured on RNAi plate at $20^{\circ} \mathrm{C}$ for 3 days (L1 larva) or 1 day (adult). The number of eggs laid by each worm for $24 \mathrm{~h}$ was counted.

Table 2 Primers for RT-PCR

\begin{tabular}{|c|c|c|}
\hline Gene & Forward & Reverse \\
\hline$s b p-1$ & GTCGGATCCTCAGTCATGCCTTAGACC & TATGGTACCGACATAGGGACGTCTCCC \\
\hline fat -1 & CATGTCGACACGCAGTACTGAATAGCC & TATGGATCCAACCAGAACATCTCCGCC \\
\hline fat -2 & TATGGATCCTCCAGGTAGTCAGTACG & CAGGGTACCTTGATTGTATCAAGGTCC \\
\hline fat-4 & CATGTCGACTTCCTCCTTACTCAACGG & TATGATCCCTCATGCTCTTGCTCTCG \\
\hline fat -5 & CATGTCGACCTGCCAATCACAACACCG & TATGGATCCGATCTCGTTCAGGTCCGC \\
\hline fat-6 & CATGGATCCTGTCACACAACACTGAGC & TATGGTACCTCCACGGCGAGATATTGC \\
\hline elo-2 & CATGGATCCTGACGACATCTTACATCG & TATGGTACCTCAGTCTGATCCAGACTC \\
\hline acs -2 & CAGGTCGACTTGCATGTCTGTGAGACC & ATAGGTACCGTGCTTGTGAGCACGTGG \\
\hline
\end{tabular}

PCR was performed using the primers indicated as below under optimal amplification conditions $\left(95^{\circ} \mathrm{C}\right.$ for 5 min; $25-30$ cycles of $95^{\circ} \mathrm{C}$ for $1 \mathrm{~min}, 52^{\circ} \mathrm{C}$ for $30 \mathrm{~s}, 72^{\circ} \mathrm{C}$ for $1.5 \mathrm{~min} ; 72^{\circ} \mathrm{C}$ for $7 \mathrm{~min}$ ) for each gene 
RNA preparation and PCR

Batches of 100 worms were collected after culture on RNAi plates for $96 \mathrm{~h}$, and RNA was extracted by the acidGTC-phenol method. Genomic DNA was digested by treatment with DNase I (Takara) for $60 \mathrm{~min}$ at $37^{\circ} \mathrm{C}$, and then RNA was repurified by repeating the acid-GTC-phenol extraction. cDNA was synthesized by using M-MLV reverse transcriptase (Takara) and used for PCR. The quantity of cDNA was corrected by using gpd-1 (glyceraldehyde 3-phosphate dehydrogenase) as an internal standard. PCR $\left(95^{\circ} \mathrm{C}\right.$ for $5 \mathrm{~min}$; $23-35$ cycles of $95^{\circ} \mathrm{C}$ for
Fig. 1 Effect of sugar on the fat accumulation in nematode. a The synchronized L1 larva was bred on the NGM plate containing glucose $(0,0.1,1,2$, $5,10,50$ and $100 \mathrm{mM}$ ) with E. coli. After 4 days, the fat was dyed with Nile red and observed under a fluorescent microscope. Upper panel: bright field, middle panel: fluorescent field (Nile red), lower panel: fluorescent field (Nile red), magnified. b The synchronized L1 larva was bred on the NGM plate containing various types of sugars $(10 \mathrm{mM})$ with $E$. coli. After 4 days, the fat was dyed with Nile red and observed under a fluorescent microscope. Upper panel: bright field, middle panel: fluorescent field (Nile red), lower panel: fluorescent field (Nile red), magnified. c, d Fluorescent intensity of Nile red in (a) and (b) was quantified and plotted on graph, respectively. $N=12$, error bar indicates standard error
A

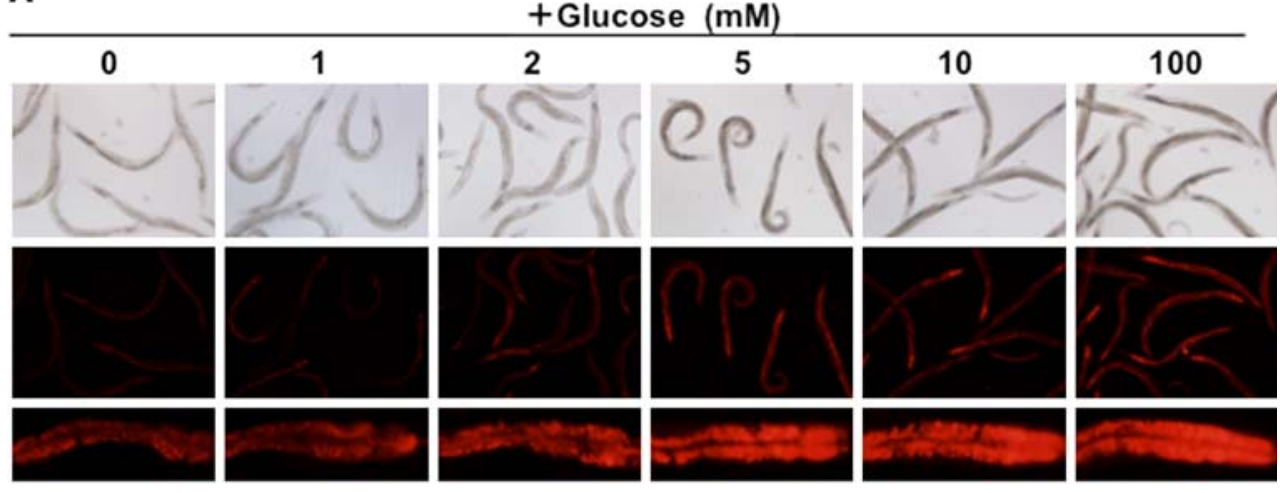

B

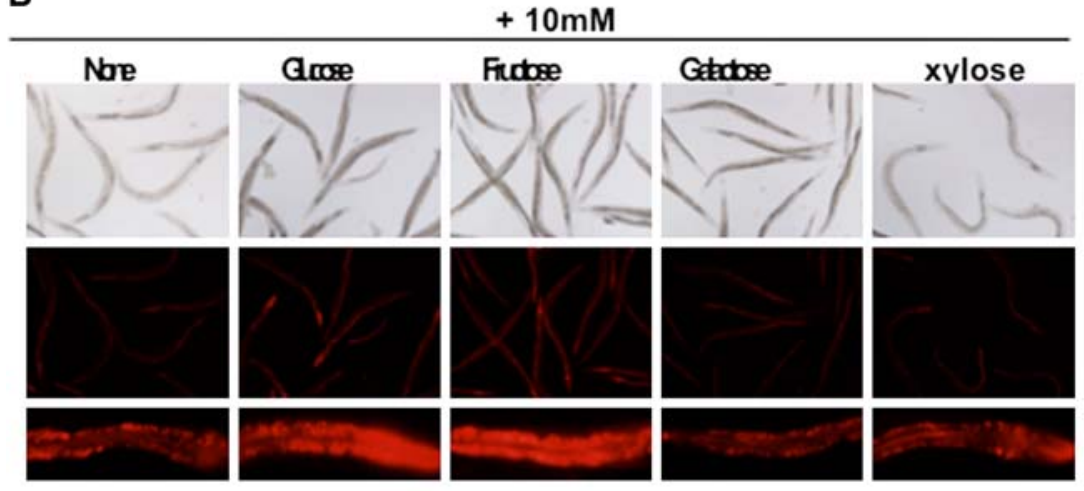

C

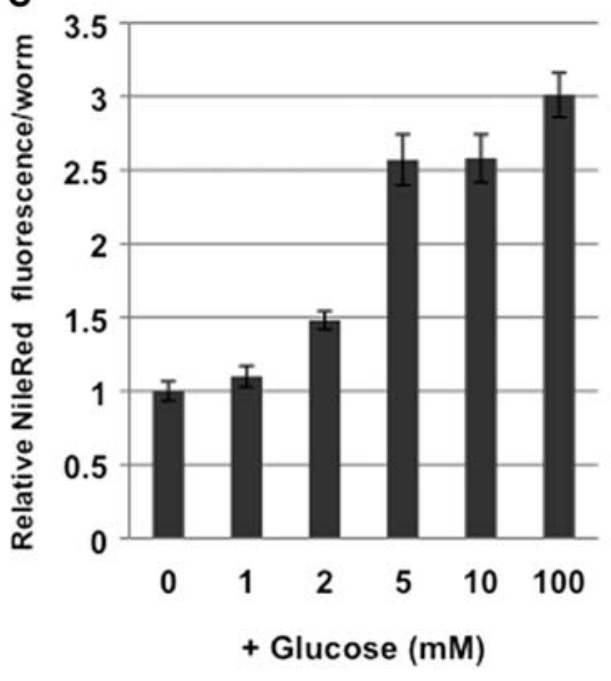

D

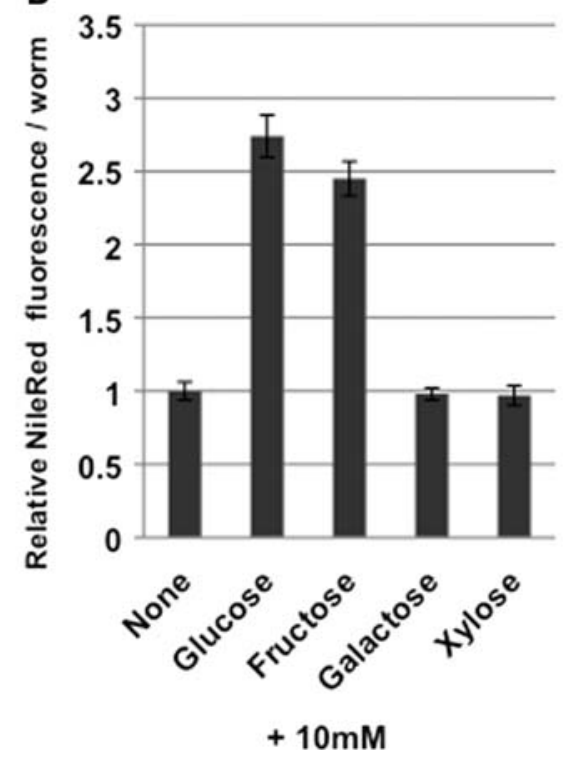


$1 \mathrm{~min}, 52^{\circ} \mathrm{C}$ for $30 \mathrm{~s}, 72^{\circ} \mathrm{C}$ for $1.5 \mathrm{~min} ; 72^{\circ} \mathrm{C}$ for $7 \mathrm{~min}$ ) was performed using each primer (Table 1).

Transgenic worm carrying promoter-GFP plasmids

The promoter regions of each gene were amplified by PCR using the primers (Table 2). Primer was designed to have each restriction site at $5^{\prime}$-end. Each genetic sequence was referred to wormbase (http://www.wormbase.org). PCR was performed using PCR-2720 (Applied Biosystems, Foster City, CA, USA) under optimal amplification conditions $\left(95^{\circ} \mathrm{C}\right.$ for $5 \mathrm{~min}$; $25-30$ cycles of $95^{\circ} \mathrm{C}$ for $1 \mathrm{~min}$, $52^{\circ} \mathrm{C}$ for $30 \mathrm{~s}, 72^{\circ} \mathrm{C}$ for $1.5 \mathrm{~min} ; 72^{\circ} \mathrm{C}$ for $7 \mathrm{~min}$ ) for each gene. The PCR products were subjected to restriction digestion and subcloned into GFP expression plasmid pPD95.77. These constructs were injected into lin-15 mutant worm (n765ts) with lin-15 expression plasmid, pDLH98, to have worm that stably expresses $g f p$. The transgenic worms at L1 stage were bred on RNAi plate for $72 \mathrm{~h}$ at $23^{\circ} \mathrm{C}$, fixed in PFA solution, and was observed under fluorescent microscope (DMRXA, Leica) with L5 filter (505 nm, Leica).

\section{Results}

\section{Effect of sugars on fat accumulation}

After adding glucose to culture dishes containing C. elegans, we observed a considerable increase in fluorescence from the Nile red staining that was used to monitor fat levels, indicating an increase in intracellular fat (Fig. 1a). The fat content started increasing with $2 \mathrm{mM}$ glucose and continued to rise with increasing concentrations of glucose in a dosedependent manner. Fat levels also increased considerably in the presence of fructose or mannose but not in the presence of galactose or xylose (Fig. 1b).

\section{Effect of glucose on gene expression}

Caenorhabditis elegans worms were grown on NGM plates containing glucose for 12 or $24 \mathrm{~h}$ and then prepared for analysis to determine the expression of various genes. We found that in the presence of glucose, sbp-1 mRNA levels increased markedly and that all other mRNA levels, except fat-2 mRNA, increased at least after $12 \mathrm{~h}$ (Fig. 2a). We then evaluated $s b p-1$ expression in transgenic worms containing a plasmid with a GFPlabeled $s b p-1$ promoter region. Using fluorescent microscopy, we found that GFP fluorescence was intense throughout the developmental stages of worm, especially in the intestine (Fig. 2b).

\section{Effect of $s b p-1$ knockdown on phenotype}

Caenorhabditis elegans worms with an sbp-1 knockdown achieved through RNAi feeding acquired a phenotype called "Clear," which is characterized by a relatively transparent body (Fig. 3a). Nile red analysis indicated a decrease in the amount of fat stored in these animals and, as was reported previously, a decrease in body size and delayed growth (Fig. 3a). Additionally, the number of eggs laid decreased considerably (Fig. 3b), and 5-6 days after being laid, many of them hatched inside the body (Fig. 3c). The number of thrashing and pumping movements was not affected, however (Fig. 3d).

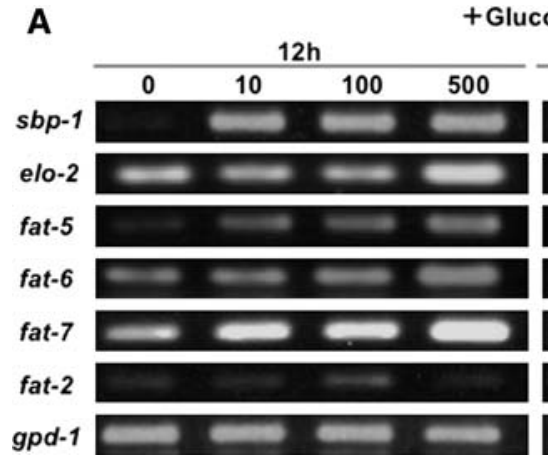

Fig. 2 Effect of glucose on the gene expression. a The synchronized L1 larva was bred on the NGM plate for 3 days. After $100 \mu \mathrm{l}$ of glucose $(0,10,100$ and $500 \mathrm{mM})$ was added on the plate, the worms were cultured for 12 or $24 \mathrm{~h}$ with $E$. coli. The quantity of cDNA was corrected by using gpd-1 (glyceraldehyde 3-phosphate dehydrogenase) as an internal standard. PCR $\left(95^{\circ} \mathrm{C}\right.$ for $5 \mathrm{~min} ; 23-35$ cycles of $95^{\circ} \mathrm{C}$ for $1 \mathrm{~min}, 52^{\circ} \mathrm{C}$ for $30 \mathrm{~s}, 72^{\circ} \mathrm{C}$ for $1.5 \mathrm{~min} ; 72^{\circ} \mathrm{C}$ for $7 \mathrm{~min}$ ) was
B

\begin{tabular}{|cccc|}
\multicolumn{4}{c}{$24 \mathrm{~h}$} \\
\hline 0 & $10^{2}$ & 100 & 500 \\
\hline & & & \\
\hline & & & \\
\hline & & & \\
\hline & & & \\
\hline & & & \\
\hline & & & \\
\hline & & & \\
\hline & & & \\
\hline & & & \\
\hline & & & \\
\hline
\end{tabular}

performed. b The GFP-expression plasmid that carries the promoter region of $s b p-1$ (the upstream 3,500 ntds region and the part of 1st exon) was constructed. This sbp-1 promoter-GFP plasmid was injected with lin-15 plasmid into the lin-15 mutant worm, and worms were observed under a fluorescence microscope through the developmental process. Bar $=500 \mu \mathrm{m}$ 
A

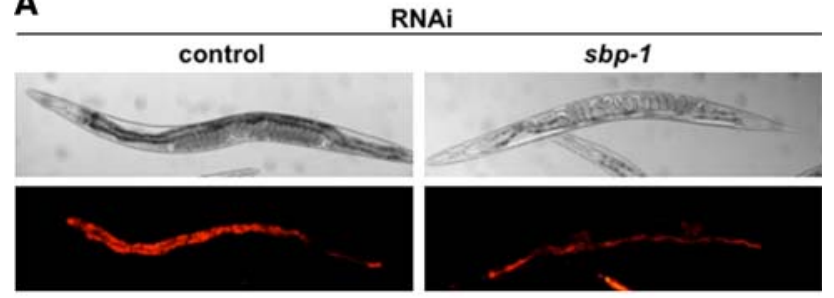

B

(a) egg laying

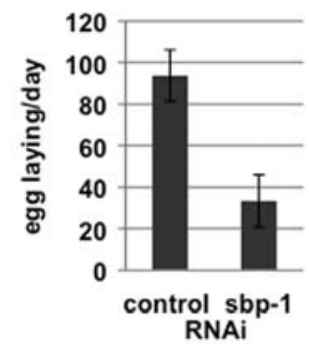

C

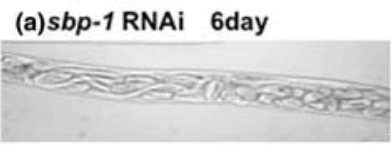

D

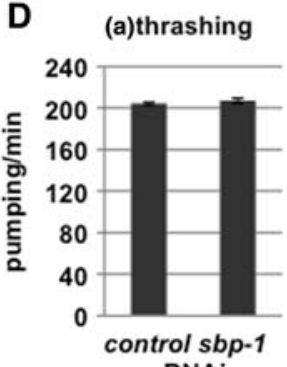

RNA (b) egg laying (adult RNAi)

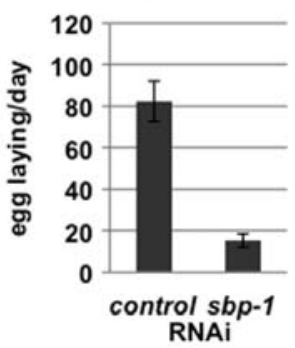

(b)stavation 1day

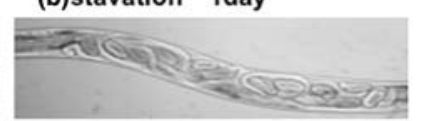

(b)pumping

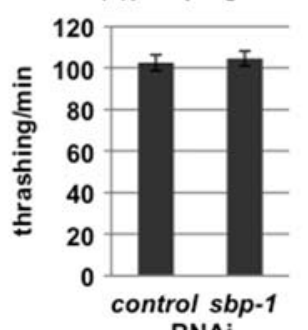

RNAi

Fig. 3 Effect of $s b p-1$ RNAi on the phenotype of nematode. (A) The synchronized worms were bred on the RNAi plate (control (L4440), $s b p-1)$ for 4 days. Then, the fat was dyed with Nile red and observed under a fluorescent microscope. The upper panel indicates an optical figure, and the lower panel indicates fluorescent figure. (B) (a) The synchronized worms were bred on the RNAi plate (control (L4440), $s b p-1)$ for 4 days, and the number of laid egg per day was counted. $N=12$, (b) The adult worms were bred on the RNAi plate (control (L4440), $s b p-1)$ for $24 \mathrm{~h}$, and the number of laid egg per day was counted. $N=9$, error bar indicates standard error. (C) (a) The synchronized worms were bred on the RNAi plate (control (L4440), $s b p-1$ ) for 6 days. (b) The wild-type adult worm was bred for 1 day without feeding (a state of starvation). (D) The synchronized worms were bred on the RNAi plate (control (L4440), sbp-1) for 4 days. The number of movements per $1 \mathrm{~min}$ of the thrashing $(a)$ and the pumping (b) was counted under a microscope. $N=9$, error bar indicates standard error

\section{Effect of $s b p-1$ knockdown on gene expression}

To determine whether SBP-1 is involved in regulating the expression of genes involved in fatty acid biosynthesis, we evaluated their RNA levels in animals with knockdown

$s b p-1$. RT-PCR analysis revealed a considerable decrease in the expression of fat-2, fat-5, fat-6, fat-7, and elo-2 (Fig. 4a) and an increase in the expression of the starvation-inducible acyl-coA synthetase (acs)-2. In situ GFP analysis of the expression of genes that induce fatty acid biosynthesis revealed fat-2, fat-5, fat-6, and elo-2 in the intestine, fat- 1 in the neural area, and fat-4 in both areas (Fig. 4b). An sbp-1 RNAi feeding reduced GFP expression in the intestine, which facilitated the detection of fat-4 expression in the neural area. It also increased the expression of acs- 2 .

Effect of fatty acids on phenotype in C. elegans with $s b p-1$ knockdown

L1 worms were bred on NGM plates each containing $1 \mathrm{mM}$ of stearic, oleic, or linoleic acid. Animals with $s b p-1$ knockdown that were exposed to oleic or linoleic acid demonstrated a restoration in body size close to that of wild-type worms (Fig. 5a). This was not observed in the presence of stearic acid. None of the knockdown animals exposed to any of these fatty acids demonstrated a restoration in fat accumulation to control levels (Fig. 5a). However, exposure to oleic or linoleic acid was followed by an increase in the number of eggs laid each day to $60 \%$ that of controls (Fig. 5b), as well as suppression of acs-2 expression in $s b p-1$ knockdown worms (Fig. 6a) and suppression of GFP-labeled acs-2 promoter activity in transgenic worms (Fig. 6b).

\section{Discussion}

Influence of sugar on fat accumulation in C. elegans

Fat accumulation increased when glucose or fructose was used as an energy source (Fig. 1); galactose and xylose (a sugar that resolves only minimally) had little effect. These observations suggest that fat levels increase with the intake of excess calories from sugar in C. elegans as they do in mammals. In mammals, acylglycerol triglyceride levels increase through up-regulation of the bHLH transcription factor SREBP-1c under the influence of nutritional status, glucose and insulin [6, 8-15, 44]. Previous reports suggest that the function of the SREBP homolog SBP-1 in nematodes is similar to that of SREBP in mammals. We investigated this possibility further by monitoring $s b p-1$ expression in L1 worms grown in the presence of $10 \mathrm{mM}$ glucose. RT-PCR analysis revealed that $s b p-1$ expression did not change throughout the maturation process. However, larvae that matured in the absence of glucose developed into adult worms that expressed $s b p-1$ when exposed to 10,100 , or $500 \mathrm{mM}$ of glucose during adulthood 
Fig. 4 Effect of $s b p-1$ RNAi on the gene expression. a The synchronized L1 worms were bred on the RNAi plate (control (L4440), sbp-1) for 3 days. The quantity of cDNA was corrected by using gpd-1 as an internal standard. b The promoter-GFP plasmids of each fatty acid composition-enzyme gene was prepared and injected into the worms to make transgenic worms. The synchronized L1 worms were bred on the RNAi plate (control (L4440), sbp-1) for 3 days and were observed under a fluorescence microscope
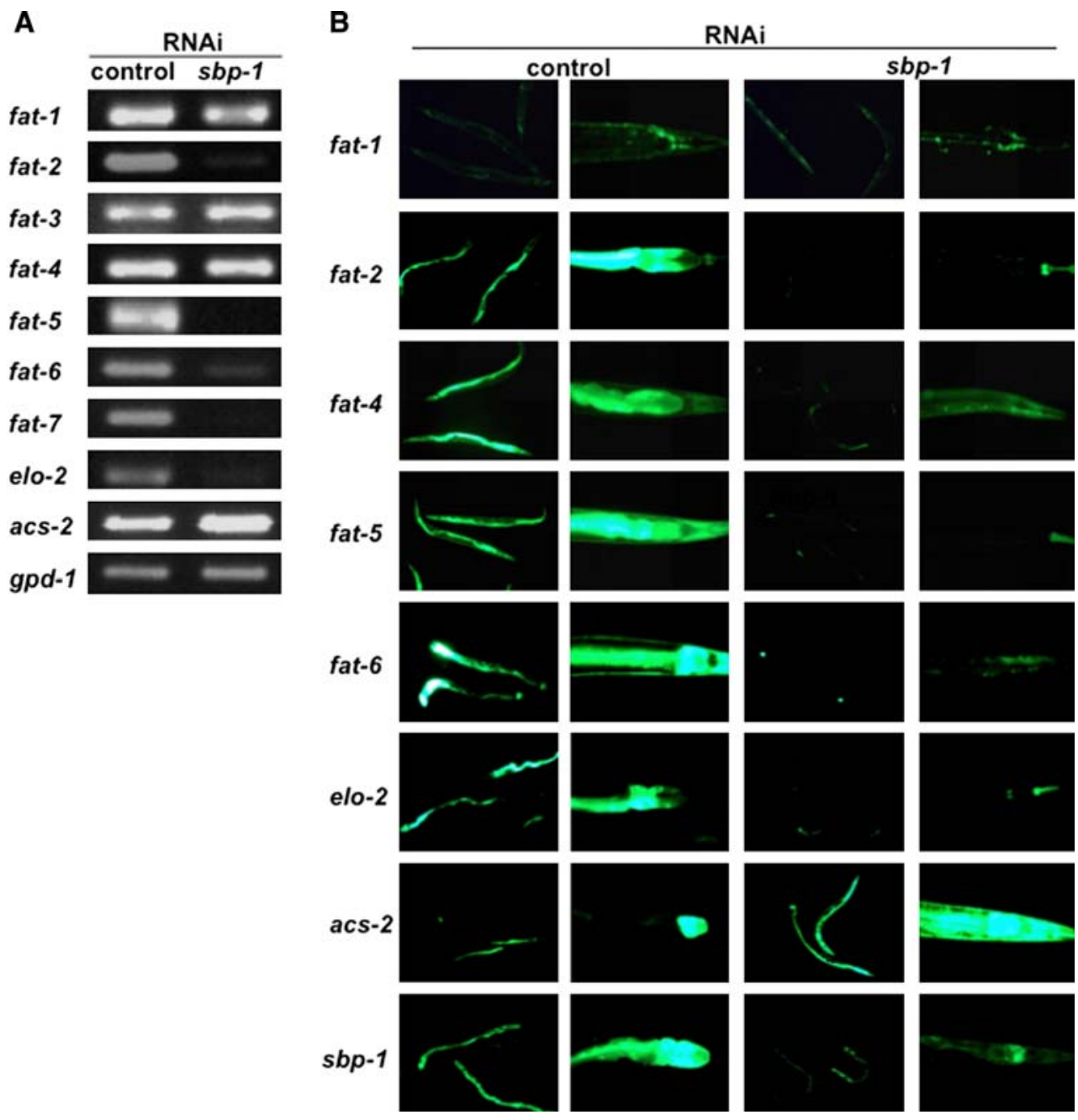

(Fig. 1). This suggests that the mechanism responsible for regulation of $s b p-1$ expression in response to the intake of excess calories from glucose is preserved in $C$. elegans as is that for SREBP-1c in mammals.

SBP-1 regulates the phenotype of C. elegans

In situ analysis of gene expression in transgenic worms carrying a GFP-labeled $s b p-1$ promoter region revealed that $s b p-1$ expression occurs primarily in the intestine, regardless of the developmental stage of the worm (Fig. 2b). This supports an earlier hypothesis that the intestine is the organ of fat accumulation in nematodes [29]. So far, our understanding of the role of SBP-1 in nematodes is limited. In this study, an $s b p-1$ knockdown through feeding RNAi resulted in a reduction in the fat content of the worm, as well as in body size and egg-laying activity (Fig. 3) -all of which are the characteristics of starvation and the presence of an eat-2 mutant [45]. Under starvation conditions, fatty acid combustion occurs following a decrease in fat-7 expression and an increase in acs- 2 expression [40, 41]. In the same way, $\beta$-oxidization was induced and weight was not changed by feeding the high fat food in mouse that lacked $\Delta 9$ stearoyl-CoA desaturase (SCD-1) (Dobrzyn et al. 2005). It has been reported that the fat-7 expression decreases in $s b p-1$ knockdown worms and that egg-laying activity is reduced in $s b p-1$ knockdown worms $[33,38]$. Our observations correspond with these findings. Moreover, in sbp-1 knockdown animals, fat-7 expression decreased and acs-2 expression increased (Fig. 4a). It is not clear, however, why the number of eggs laid decreased.

SBP-1 regulates the expression of genes responsible for fatty acid synthesis

SBP-1 appears to be involved in the expression of genes that participate in fatty acid synthesis, as indicated by decreased expression of acc- 1, fas- 1, fat -6 , and fat-7 in sbp-l knockdown worms [29, 33]. The nematode has $\Delta 12$ and $\Delta 3$ desaturases (these are absent in most mammals), which convert saturated fatty acids into mono- or 
Fig. 5 Effect of fatty acid on the phenotypes of $s b p-1$ RNAi worm. a The synchronized L1 worms were bred on the RNAi plate (control (L4440), sbp-1) containing $1 \mathrm{mM}$ fatty acids (ste: stearic acid, ole: oleic acid, lino: linoleic acid) for 4 days, and the fat accumulation was observed under a microscope. Bar $=500 \mu \mathrm{m}$. b The synchronized worms were bred on the RNAi plate (control (L4440), sbp-1) containing $1 \mathrm{mM}$ fatty acids (ste: stearic acid, ole: oleic acid, lino: linoleic acid) for 3 days, and the number of laid egg per day was counted. $N=9$, error bar indicates standard error
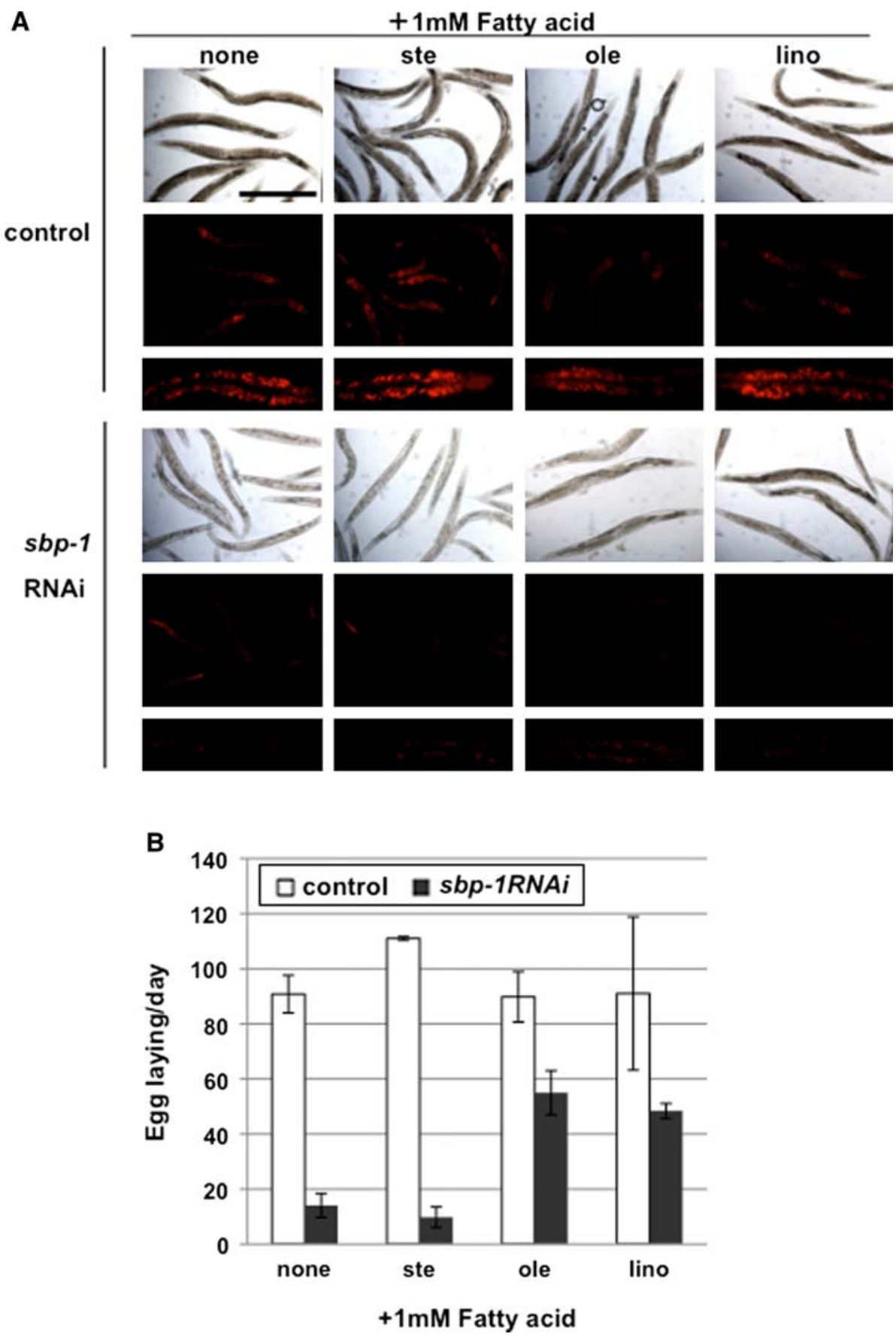

polyunsaturated fatty acids. So far, the role of $\Delta 12$ or $\Delta 3$ desaturases in C. elegans is not completely understood. To explore their relationship with SBP-1, we used RT-PCR to determine whether $s b p-1$ knockdown in these animals affects desaturase activity: we found that elo-2, fat-2, fat-5, fat-6, and fat-7 expression increased remarkably in these worms, indicating that the gene products are regulated by SBP-1. By contrast, fat-1, fat-3, and fat-4 expression did not change (Fig. 4a), indicating that their products are either regulated by other factor or controlled by multiple mechanisms. The relationship between the $\Delta 12$ desaturases (which are involved in the production of linoleic acid [C18:2]) and SBP-1 remains inconclusive, given that one $\Delta 12$-desaturase-producing gene (fat-2) responded to the sbp-1 knockdown and another (fat-1) did not. Because the $\Delta 12$ desaturases are not found in humans or mice, we cannot look to mammals for potential similarities in control and function. So far, little is known about factors contributing to the expression of fat-1 in C. elegans. Our in situ GFP analysis of transgenic worms revealed that this gene is 
Fig. 6 Effect of fatty acid on the gene expression of $s b p-1$ RNAi worm. a The synchronized L1 worms were bred on the RNAi plate (control (L4440), sbp-1) containing $1 \mathrm{mM}$ fatty acids (ste: stearic acid, ole: oleic acid, lino: linoleic acid) for 3 days, and RT-PCR was performed. The quantity of cDNA was corrected by using gpd-1 as an internal standard. b The synchronized transgenic worm that carries the acs-2 promoter-GFP plasmid was bred on the RNAi plate (control (L4440), sbp-1) containing $1 \mathrm{mM}$ fatty acids (ste: stearic acid, ole: oleic acid, lino: linoleic acid) for 4 days and was observed under a fluorescence microscope

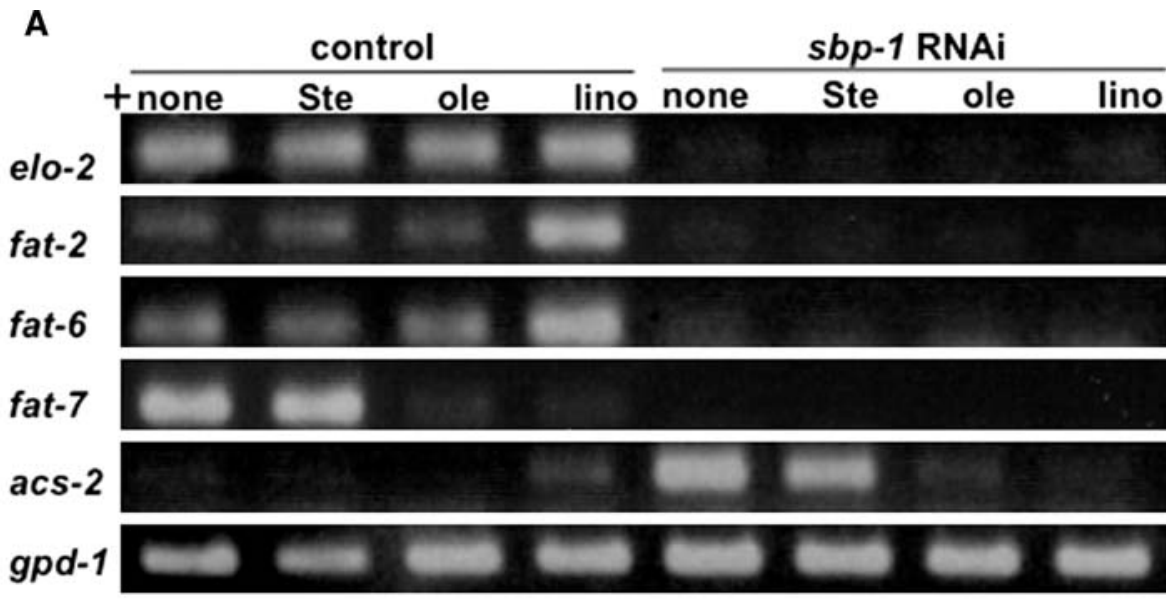

B

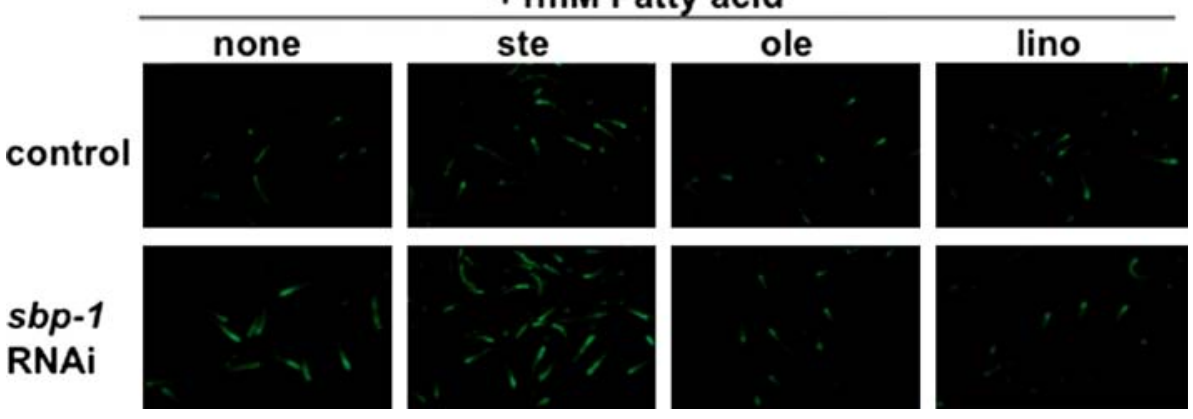

expressed only in the neural area (Fig. 4b). The GFP level in the neural area was not affected when feeding $s b p-1$ RNAi was introduced to these worms, which suggests that fat-1 is not regulated by SBP-1.

More information is available about the $\Delta 9$-desaturases-fat-5, fat-6, and fat-7-and the elo- 2 that responded to SBP-1 in our study. An elo-2 knockdown causes delayed growth and other effects in nematodes [46]; this is consistent with the effects of palmitic acid elongase, which is controlled by SREBP-1c in mammals. Recent reports that a knockdown of the gene for another fatty acid elongaseelovl6 - causes insulin resistance in mice [47] suggest a clinical role for elo-2 that may be worthy of further investigation. Knockdowns of fat-5, fat-6, and fat-7 or a mutation in fat- 6 and fat-7 cause severely delayed growth and a decreased accumulation of fat in C. elegans [36]. Additional information is available concerning the regulation of these genes: fat-7 expression is induced through activation of the nuclear receptor nhr-80 in animals carrying a fat-6 mutant [39]; and fat-5, fat-7, and acs-2 expression is activated by nhr-49 through its interactions with mdt-15 and SBP-1 [33, 42]. The failure of fat-3 (a $\Delta 5$ desaturase) and fat 4 (a $\Delta 6$ desaturase) to respond to an $s b p-1$ knockdown suggests that they are controlled by another entity or that they respond to multiple controls. The latter is suggested in mammals by the change in mRNA levels for genes coding the $\Delta 5$ and $\Delta 6$ desaturases that occurs in response to changes in both SREBP-1c and PPAR- $\gamma$ activity. In this case, the loss of function by one transcription factor can be compensated for by the other [19].

In situ analysis of gene expression in transgenic worms carrying a GFP-labeled promoter region of fat-4 revealed that fat 4 is expressed predominantly in the intestine (Fig. 4b). The introduction of $s b p-1$ RNAi feeding into these worms caused GFP fluorescence in the intestine to decrease and allowed fat-4 expression to be detected in the neural area. Because the RNAi feeding method is not available for neurons, changes in fat-4 expression cannot be detected by RT-PCR (Fig. 4a). It has been hypothesized that PUFAs such as DHA and EPA have important roles in central nerve function [48, 49]. Recently, it was suggested that the schizophrenia-related gene $F A B P 7$ participates in the uptake of PUFAs into the neuron [50] and that the neuronal damage responsible for Parkinson's disease in murine studies is mitigated with the uptake of PUFAs [51]. Because the expression of fat-1, fat-4 (Fig. 4b), and fat-3 $[36,52]$ was detected in the neural area, it has been suggested that these animals produce PUFAs endogenously for their own use. 
The effect of fatty acid on the phenotype of $s b p-1$ RNAi worm

In vitro exposure of L1 worms with $s b p-1$ knockdown to oleic or linoleic acid restored body size but did not restore the accumulation of fat (Fig. 5a). However, when RNAi worms of fat-6, fat-7, and fat-2 (which participate in endogenous PUFA biosynthesis) were exposed to oleic or linoleic acid, fat accumulation was restored (data not shown). This suggests that SBP-1 possibly affects the expression of genes concerned with fat accumulation as well as genes concerned with the biosynthesis of fatty acids. In fact, SREBP controls the expression of genes involved in triglyceride composition in mammals. The $s b p-1$ knockdown phenotypes ("Clear" and "inside hatching") observed in this study are similar to those seen in worms bred under starvation conditions. Consistent with this, we observed an increase in the expression of the starvation-inducible gene $a c s-2$ in $s b p-1$ RNAi worms (Fig. 4b). It is known that acs-2 expression is upregulated in fat- 6 and fat-7 mutants and in fat- 6 and fat-7 knockdown animals. Thus far, there have been no reports that a lack of oleic acid induces acs-2 expression or $\beta$-oxidation of fatty acids. In our study, exposure of $s b p-1$ knockdown worms to oleic acid actually suppressed acs-2 expression (Fig. 6a). The same effect was achieved with linoleic acid, however, which complicates the interpretation of our results. Body size and the number of eggs laid by $s b p-1$ knockdown worms were restored to normal through exposure to oleic or linoleic acid (Fig. 5), and it has been suggested that these fatty acids have similar effects. However, additional studies involving other unsaturated fatty acids and an analysis of the fatty acid content of the worm are required to confirm this hypothesis.

In this study, we found that the uptake of excess calories from sugar results in the accumulation of fat in C. elegans, as it does in mammals. The mechanism for fat accumulation is almost the same in C. elegans as it is in mammals, which suggests that this nematode could be a time-saving and cost-effective alternative for studying fat metabolism.

Acknowledgments This work was supported in part by Grants-inAid for Scientific Research from the Ministry of Education, Science, Sports, and Culture of Japan. We wish to thank Dr. Motomichi Doi (Advanced Industrial Science and Technology, Neuroscience Research Institute) for technical help for microinjection.

\section{References}

1. Deeney JT, Prentki M, Corkey BE (2000) Metabolic control of $\beta$-cell function. Cell Dev Biol 11:267-275

2. Watson RT, Kanzaki M, Pessin JE (2004) Regulated membrane trafficking of the insulin-responsive glucose transporter 4 in adipocytes. Endocr Rev 25:177-204
3. Bryant NJ, Govers R, James DE (2002) Regulated transport of the glucose transporter Glut-4. Nat Rev Mol Cell Biol 3:267-277

4. Watson RT, Pessin JE (2001) Subcellular compartmentalization and trafficking of the insulin-responsive glucose transporter, Glut-4. Exp Cell Res 271:75-83

5. Simpson F, Whitehead JP, James DE (2001) Glut-4-at the cross roads between membrane trafficking and signal transduction. Traffic 2:2-11

6. Shimomura I, Bashmakov Y, Ikemoto S, Horton JD, Brown MS, Goldstein JL (1999) Insulin selectively increases SREBP-1c mRNA in the livers of rats with treptozotocin-induced diabetes. Proc Natl Acad Sci USA 96:13656-13661

7. Foretz M, Guichard C, Ferre P, Foufelle F (1999) Sterol regulatory element binding protein- $1 \mathrm{c}$ is a major mediator of insulin action on the hepatic expression of glucokinase and lipogenesisrelated genes. Proc Natl Acad Sci USA 96:12737-12742

8. Azzout MD, Becard D, Guichard C, Foretz M, Ferre P, Foufelle F (2000) Insulin effects on sterol regulatory-element-binding protein-1c (SREBP-1c) transcriptional activity in rat hepatocytes. Biochem J 350:389-393

9. Becard D, Hainault I, Azzout MD, Bertry CL, Ferre P, Foufelle F (2001) Adenovirus-mediated overexpression of sterol regulatory element- binding protein-1c mimics insulin effects on hepatic gene expression and glucose homeostasis in diabetic mice. Diabetes 50:2425-2430

10. Matsumoto M, Ogawa W, Teshigawara K, Inoue H, Miyake K, Sakaue H, Kasuga M (2002) Role of the insulin receptor substrate 1 and phosphatidylinositol 3-kinase signaling pathway in insulininduced expression of sterol regulatory element-binding protein $1 \mathrm{c}$ and glucokinase genes in rat hepatocytes. Diabetes 51:16721680

11. Kim JB, Sarraf P, Wright M, Yao KM, Mueller E, Solanes G, Lowell BB, Spiegelman BM (1998) Nutritional and insulin regulation of fatty acid synthetase and leptin gene expression through ADD1/SREBP1. J Clin Invest 101:1-9

12. Bizeau ME, MacLean PS, Johnson GC, Wei Y (2003) Skeletal muscle sterol regulatory element binding protein-1c decreases with food deprivation and increases with feeding in rats. J Nutr 133:1787-1792

13. Commerford SR, Peng L, Dube JJ, O'Doherty RM (2004) In vivo regulation of SREBP-1c in skeletal muscle: effects of nutritional status, glucose, insulin and leptin. Am J Physiol Regul Integr Comp Physiol 287:R218-R227

14. Brown MS, Goldstein JL (1999) A proteolytic pathway that controls the cholesterol content of membranes, cells, and blood. Proc Natl Acad Sci USA 96:11041-11048

15. Kim JB, Spotts GD, Halvorsen YD, Shih HM, Ellenberger T, Towle HC, Spiegelman BM (1995) Dual DNA binding specificity of ADD1/SREBP1 controlled by a single amino acid in the basic helix-loop-helix domain. Mol Cell Biol 15:2582-2588

16. Magaña MM, Lin SS, Dooley KA, Osborne TF (1997) Sterol regulation of acetyl coenzyme A carboxylase promoter requires two interdependent binding sites for sterol regulatory element binding proteins. J Lipid Res 38:1630-1638

17. Bennett MK, Lopez JM, Sanchez HB, Osborne TF (1995) Sterol regulation of fatty acid synthase promoter. Coordinate feedback regulation of two major lipid pathways. J Biol Chem 270:2557825583

18. Tabor DE, Kim JB, Spiegelman BM, Edwards PA (1998) Transcriptional activation of the stearoyl-CoA desaturase 2 gene by sterol regulatory element-binding protein/adipocyte determination and differentiation factor 1. J Biol Chem 273:22052-22058

19. Matsuzaka T, Shimano H, Yahagi N, Amemiya-Kudo M, Yoshikawa T, Hasty AH, Tamura Y, Osuga J, Okazaki H, Iizuka Y, Takahashi A, Sone H, Gotoda T, Ishibashi S, Yamada N (2002) 
Dual regulation of mouse Delta(5)- and Delta(6)-desaturase gene expression by SREBP-1 and PPARalpha. J Lipid Res 43:107-114

20. Ericsson J, Jackson SM, Kim JB, Spiegelman BM, Edwards PA (1997) Identification of glycerol-3-phosphate acyltransferase as an adipocyte determination and differentiation factor 1- and sterol regulatory element-binding protein-responsive gene. J Biol Chem 272:7298-7305

21. Shimano H (2002) Sterol regulatory element-binding protein family as global regulators of lipid synthetic genes in energy metabolism. Vitam Horm 65:167-194

22. Horton JD (2002) Sterol regulatory element-binding proteins: transcriptional activators of lipid synthesis. Biochem Soc Trans 30:1091-1095

23. Kumadaki S, Matsuzaka T, Kato T, Yahagi N, Yamamoto T, Okada S, Kobayashi K, Takahashi A, Yatoh S, Suzuki H, Yamada N, Shimano H (2008) Mouse Elovl-6 promoter is an SREBP target. Biochem Biophys Res Commun 368:261-266

24. Ide T, Shimano H, Yahagi N, Matsuzaka T, Nakakuki M, Yamamoto T, Nakagawa Y, Takahashi A, Suzuki H, Sone H, Toyoshima H, Fukamizu A, Yamada N (2004) SREBPs suppress IRS-2-mediated insulin signalling in the liver. Nat Cell Biol 6:351-357

25. Tontonoz P, Kim JB, Graves RA, Spiegelman BM (1993) ADD1: a novel helix-loop-helix transcription factor associated with adipocyte determination and differentiation. Mol Cell Biol 13:47534759

26. Hughes AL, Todd BL, Espenshade PJ (2005) SREBP pathway responds to sterols and functions as an oxygen sensor in fission yeast. Cell 120:831-842

27. Kunte AS, Matthews KA, Rawson RB (2006) Fatty acid auxotrophy in Drosophila larvae lacking SREBP. Cell Metab 3:439_ 448

28. Taghibiglou C, Martin HS, Rose JK, Ivanova N, Lin CH, Lau HL, Rai S, Wang YT, Rankin CH (2009) Essential role of SBP-1 activation in oxygen deprivation induced lipid accumulation and increase in body width/length ratio in Caenorhabditis elegans. FEBS Lett 583:831-834

29. McKay RM, McKay JP, Avery L, Graff JM (2003) C. elegans: a model for exploring the genetics of fat storage. Dev Cell 4:131142

30. Kniazeva M, Crawford QT, Seiber M, Wang CY, Han M (2004) Monomethyl branched-chain fatty acids play an essential role in Caenorhabditis elegans development. PLoS Biol 2:E257

31. Ashrafi K, Chang FY, Watts JL, Fraser AG, Kamath RS, Ahringer J, Ruvkun G (2003) Genome-wide RNAi analysis of Caenorhabditis elegans fat regulatory genes. Nature 421:268272

32. Ashrafi K (2007) Obesity and the regulation of fat metabolism. wormbook 1-20

33. Yang F, Vought BW, Satterlee JS, Walker AK, Jim Sun ZY, Watts JL, DeBeaumont R, Saito RM, Hyberts SG, Yang S, Macol C, Iyer L, Tjian R, van den Heuvel S, Hart AC, Wagner G, Naar AM (2006) An ARC/Mediator subunit required for SREBP control of cholesterol and lipid homeostasis. Nature 442:700-704

34. Watts JL, Browse J (1999) Isolation and characterization of a Delta 5-fatty acid desaturase from Caenorhabditis elegans. Arch Biochem Biophys 362:175-182

35. Watts JL, Browse J (2000) A palmitoyl-CoA-specific delta9 fatty acid desaturase from Caenorhabditis elegans. Biochem Biophys Res Commum 272:263-269

36. Watts JL, Phillips E, Griffing KR, Browse J (2003) Deficiencies in C20 polyunsaturated fatty acids cause behavioral and developmental defects in Caenorhabditis elegans fat-3 mutants. Genetics 163:581-589
37. Brock TJ, Browse J, Watts JL (2007) Fatty acid desaturation and the regulation of adiposity in Caenorhabditis elegans. Genetics $176: 865-875$

38. Horikawa M, Nomura T, Hashimoto T, Sakamoto K (2008) Elongation and desaturation of fatty acids are critical in growth, lipid metabolism and ontogeny of Caenorhabditis elegans. J Biochem 144:149-158

39. Brock TJ, Browse J, Watts JL (2006) Genetic regulation of unsaturated fatty acid composition in C. elegans. PLoS Genet 2:e108

40. Van Gilst MR, Hadjivassiliou H, Jolly A, Yamamoto KR (2005a) Nuclear hormone receptor NHR-49 controls fat consumption and fatty acid composition in C. elegans. PLoS Biol 3:e53

41. Van Gilst MR, Hadjivassiliou H, Yamamoto KR (2005) A Caenorhabditis elegans nutrient response system partially dependent on nuclear receptor NHR-49. Proc Natl Acad Sci USA 102:13496-13501

42. Taubert S, Van Gilst MR, Hansen M, Yamamoto KR (2006) A Mediator subunit, MDT-15, integrates regulation of fatty acid metabolism by NHR-49-dependent and -independent pathways in C. elegans. Genes Dev 20:1137-1149

43. Brenner S (1974) The genetics of Caenorhabditis elegans. Genetics 77:71-94

44. Foretz M, Pacot C, Dugail I, Lemarchand P, Guichard C, Le Liepvre X, Berthelier-Lubrano C, Spiegelman B, Kim JB, Ferre $\mathrm{P}$, Foufelle F (1999) ADD1/SREBP-1c is required in the activation of hepatic lipogenic gene expression by glucose. Mol Cell Biol 19:3760-3768

45. McKay JP, Raizen DM, Gottschalk A, Schafer WR, Avery L (2004) eat-2 and eat-18 are required for nicotinic neurotransmission in the Caenorhabditis elegans pharynx. Genetics 166:161-169

46. Kniazeva M, Sieber M, McCauley S, Zhang K, Watts JL, Han M (2003) Suppression of the ELO-2 FA elongation activity results in alterations of the fatty acid composition and multiple physiological defects, including abnormal ultradian rhythms, in Caenorhabditis elegans. Genetics 163:159-169

47. Matsuzaka $\mathrm{T}$, Shimano $\mathrm{H}$, Yahagi N, Kato $\mathrm{T}$, Atsumi A, Yamamoto $\mathrm{T}$, Inoue $\mathrm{N}$, Ishikawa M, Okada S, Ishigaki N, Iwasaki H, Iwasaki Y, Karasawa T, Kumadaki S, Matsui T, Sekiya M, Ohashi K, Hasty AH, Nakagawa Y, Takahashi A, Suzuki H, Yatoh S, Sone H, Toyoshima H, Osuga J, Yamada N (2007) Crucial role of a long-chain fatty acid elongase, Elovl6, in obesity-induced insulin resistance. Nat Med 13:1193-1202

48. Salem N Jr, Litman B, Kim HY, Gawrisch K (2001) Mechanisms of action of docosahexaenoic acid in the nervous system. Lipids 36:945-959

49. Julien C, Berthiaume L, Hadj-Tahar A, Rajput AH, Bédard PJ, Di Paolo T, Julien P, Calon F (2006) Postmortem brain fatty acid profile of levodopa-treated Parkinson disease patients and parkinsonian monkeys. Neurochem Int 48:404-414

50. Watanabe A, Toyota T, Owada Y, Hayashi T, Iwayama Y, Matsumata M, Ishitsuka Y, Nakaya A, Maekawa M, Ohnishi T, Arai R, Sakurai K, Yamada K, Kondo H, Hashimoto K, Osumi N, Yoshikawa T (2007) Fabp7 maps to a quantitative trait locus for a Schizophrenia Endophenotype. PLoS Biol 5:e297

51. Bousquet M, Saint-Pierre M, Julien C, Salem N Jr, Cicchetti F, Calon F (2008) Beneficial effects of dietary omega-3 polyunsaturated fatty acid on toxin-induced neuronal degeneration in an animal model of Parkinson's disease. FASEB J 22:1213-1225

52. Lesa GM, Palfreyman M, Hall DH, Clandinin MT, Rudolph C, Jorgensen EM, Schiavo G (2003) Long chain polyunsaturated fatty acids are required for efficient neurotransmission in C. elegans. J Cell Sci 116:4965-4975 